W

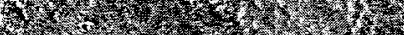

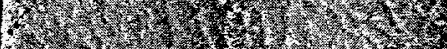

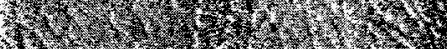
14

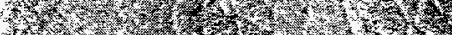

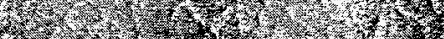

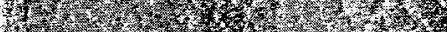

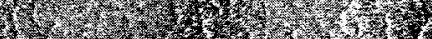

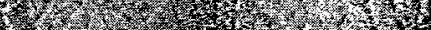

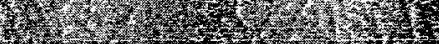

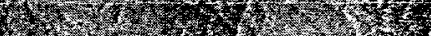

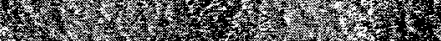

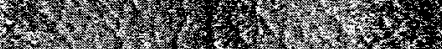

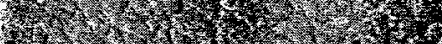
․․

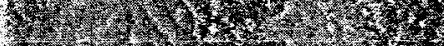

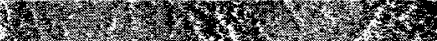
1.t. I 1.0. W , 3.7.

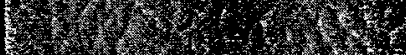

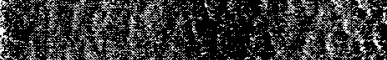

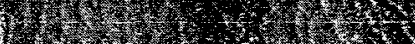

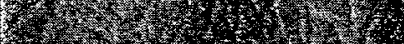
1.

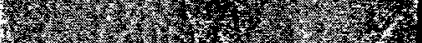

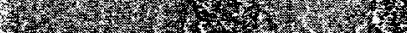

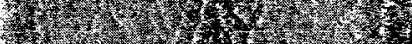

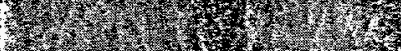

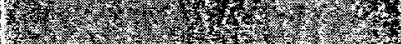

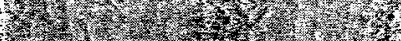

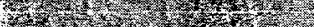

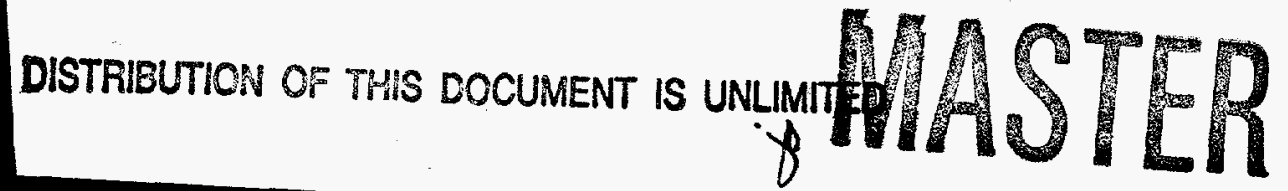

DEVELOPMENT DIVISION

OCTOBER - DECEMBER 1971

Normal Process Development

Endeavor No. $213 \& 203$

\section{HE SYNTHESIS}

D. V. Hayes

$\varepsilon$

F. I. Honea

93

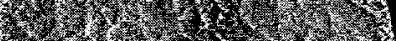
6.t. 3.

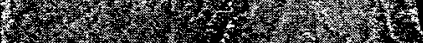

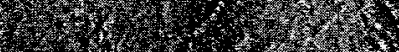

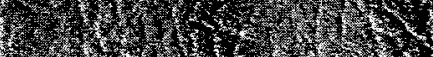
Het W

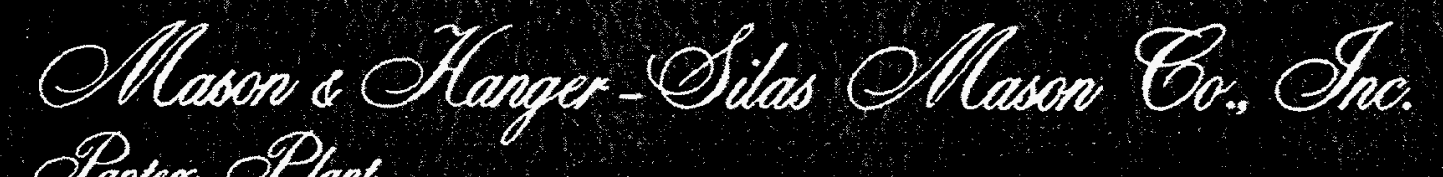

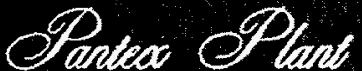

P. 0 . $80 \times 647$

AMARILLO, TEXAS 79105 $806-335-1581$ operated for the

ATOMIC ENEReY COMMISsIon

under

U. S COVFRMENT Contract DA-11-173-AMC-487 (A) 


\section{DISCLAMIER}

Portions of this document may be illegible in electronic image products. Images are produced from the best available original document. 


\title{
HE SYNTHESIS
}

\author{
D. V. Hayes \\ $\varepsilon$ \\ F. I. Honea
}

DEVELOPMENT DIVISION

The purpose of this project is to develop, maintain, and use pilot scale $(10-20$ $\mathrm{kg}$ ) synthesis of erergetic binders, plasticizers and explosives.

\section{DISCLAIMER}

This report was prepared as an account of work sponsored by an agency of the United States Government. Neither the United States Government nor any agency thereof, nor any of their employees, makes any warranty, express or implied, or assumes any legal liability or responsibility for the accuracy, completeness, or usefulness of any information, apparatus, product, or process disclosed, or represents that its use would not infringe privately owned rights. Reference herein to any specific commercial product, process, or service by trade name, trademark, manufacturer, or otherwise does not necessarily constitute or imply its endorsement, recommendation, or favoring by the United States Government or any agency thereof. The views and opinions of authors expressed herein do not necessarily state or reflect those of the United States Government or any agency thereof.

\author{
October - December 1971 \\ Endeavor No. 213 \& 203 \\ Acct. No. 22-2-44-01-213 \& 04-203
}




\section{HE SYNTHESIS}

\section{ABSTRACT}

Existing supplies of bis-trinitroanisole and picryl hydrazine were used to make $2 \mathrm{~kg}$ of bis-hexanitrohydrazobenzene.

Development of the HNAB recrystallization process was temporarily stopped due to the need to produce a supply of the intermediate products (picryl chloride and HNHB) .

Purchase orders for DINOL and DNPIA required for synthesis of AFNOL were awarded.

\section{DISCUSS ION}

\section{BIS-HNHB (BIS-HEXANITROHYDRAZOBENZENE)}

Existing supplies of picryl hydrazine(1) and Bis-TNA(2) were used to make a $12 \mathrm{~kg}$ batch of bis-HNHB (precursor to bis-HNAB).<smiles>COc1c([N+](=O)[O-])cc([N+](=O)[O-])c(-c2c([N+](=O)[O-])cc([N+](=O)[O-])c(OC)c2[N+](=O)[O-])c1[N+](=O)[O-]</smiles>

MW 484.25

Bis-TNA

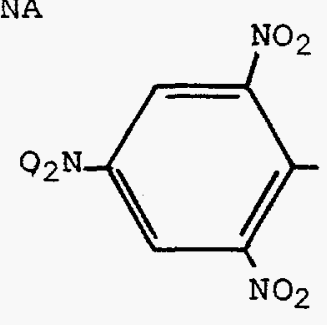

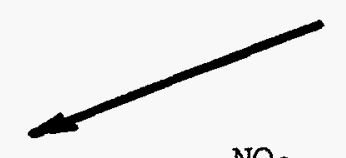

$+2$<smiles>NNc1c([N+](=O)[O-])cc([N+](=O)[O-])c([N+](=O)[O-])c1[N+](=O)[O-]</smiles>

243.14 Picryl Hydrazine

Bis $-\mathrm{HNHB}$

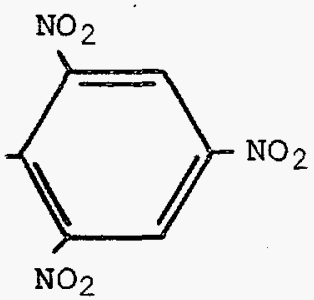

A solution of bis-TNA (6kg) and tetrahydrofuran (THF) (31 liters) was heated to $55 \mathrm{C}$ in the 200 liter reactor. A solution of picryl hydrazine ( $8 \mathrm{~kg})$, THF (31 liters) and ethanol (62 liters) was then dumped into the reactor. This mixture

(1) Synthesis of Picryl Hydrazine, D. V. Hayes and F. I. Honea, August 1970.

(2) HE Synthesis Quarterly Report, April-June 1971, D. V. Hayes and F. I. Honea. 
was heated to $45 \mathrm{C}$ and a slurry of $9700 \mathrm{~g}$ potassium acetate and 62 liters of ethanol was added rapidly to the reactor. The whole reaction mixture was heated to $55 \mathrm{C}$ for one hour then allowed to cool overnight. The reaction mixture was added to a hydrochloric acid solution in the 200-gallon reactor and mixed about 2-1/2 hours. Again, the mixture was allowed to stand overnight in the reactor. During this time the product changed from a light brown powder to a sticky black tar. The melting range for this tar was $125 \mathrm{C}$ to $185 \mathrm{C}$. The tar was recrystallized by dissolving in ethyl acetate and ethanol and precipitating in hexane. The product had a melting range of 160 to $185 \mathrm{C}$ but the yield was only $2 \mathrm{~kg}$. DTA gives no information because the product undergoes an exothermic decomposition when it melts (Fig. 1). Data from $\mathrm{CH}$ and $\mathrm{N}$ are shown in Table $\mathrm{I}$. All batches were high in carbon and hydrogen but low in nitrogen content.

Table I. CH and $\mathrm{N}$ Data for Bis-HNHB

\begin{tabular}{|c|c|c|c|c|c|}
\hline & & Sandia & Sandia & Pantex & $3-14-01$ \\
\hline Element & Theoretical $^{a}$ & $10-15-2$ & $10-11-3$ & Sample 1 & Sample 2 \\
\hline C & 31.8 & 33.4 & 32.2 & 33.3 & 35.2 \\
\hline $\mathrm{H}$ & 0.5 & 1.6 & 1.4 & 1.1 & 1.6 \\
\hline N & 24.7 & 23.5 & 21.5 & 20.4 & 20.4 \\
\hline$x^{b}$ & 43.0 & 41.5 & 44.9 & 45.2 & 42.8 \\
\hline$\Sigma$ & 100.0 & 100.00 & 100.0 & 100.0 & 100.0 \\
\hline
\end{tabular}

II。 HNAB (HEXANITROHYDRAZOBENZENE)

Approximately $44 \mathrm{kgs}$ of HNAB were synthesized and are ready for recrystallization and heat treating. A summary of the intermediate products made this quarter are shown in Table II.

Table II. Summary of HNAB Intermediate Products Picryl Chloride

$\begin{array}{ccc}\text { Batch No. } & \text { Yield }(\mathrm{kg}) & \text { \% of Theoretical } \\ 1277-05-01 & 18.8 & 94.0 \\ 1292-05-01 & 18.7 & 93.5 \\ 1293-05-01 & 19.2 & 96.0 \\ 1294-05-01 & 19.5 & 97.5 \\ 1299-05-01 & 19.1 & 95.5 \\ 1300-05-01 & 18.9 & 94.5\end{array}$




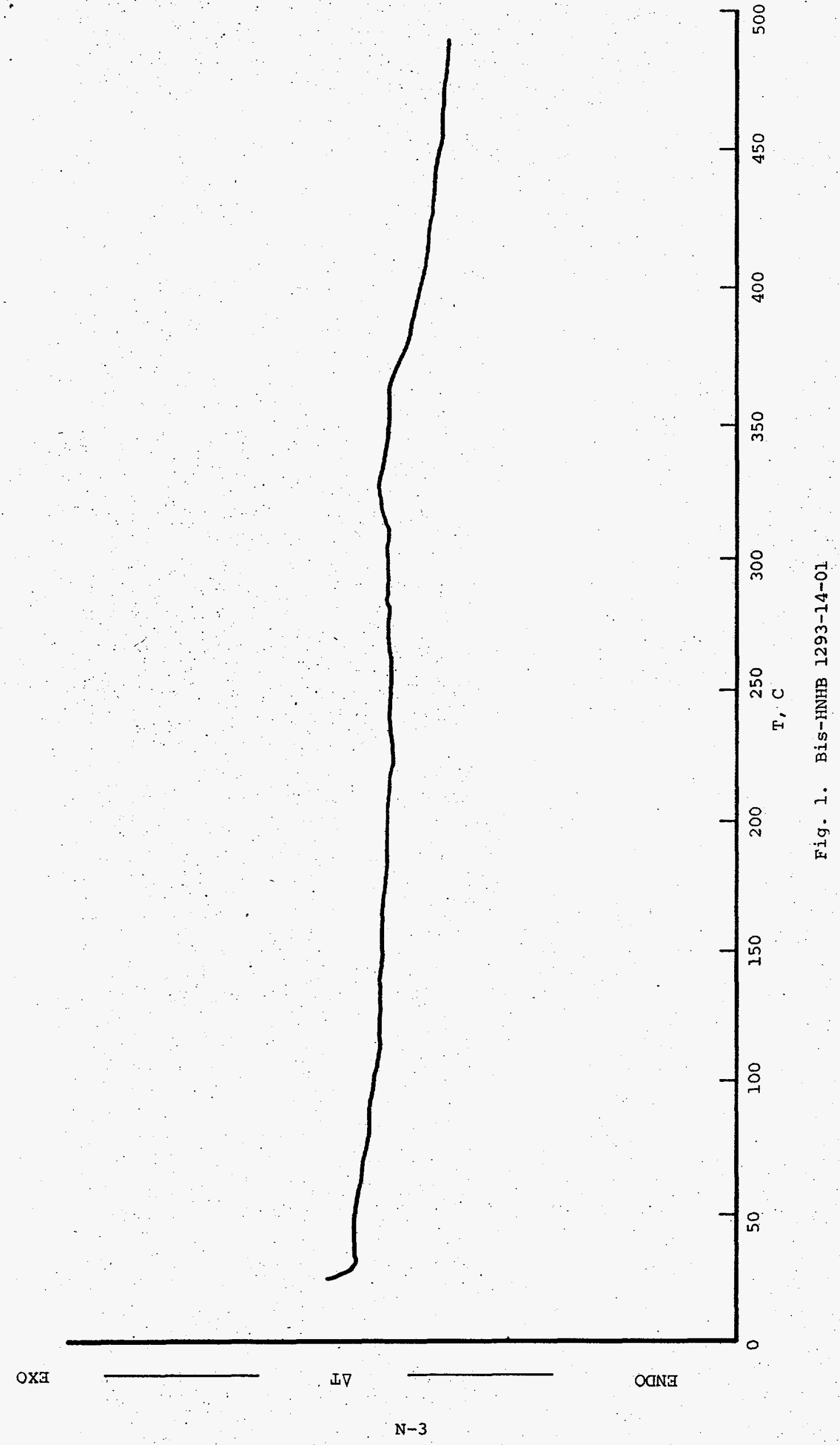


Table II. Surmary of HNAB Intermediate Products (Cont'd)

Hexanitrohydrazobenzene (HNHB)

$\begin{array}{lll}1312-10-01 & 18.0 & 90.0 \\ 1314-10-01 & 18.5 & 92.5 \\ 1320-10-01 & 19.0 & 95.0 \\ 1322-10-01 & 19.0 & 95.0\end{array}$

Recrystallization of FinHB

$\begin{array}{lll}1327-10-01 R & 3.5 & 50.0 \\ 1333-10-01 R & 3.9 & 55.0 \\ 1335-10-01 R & 4.3 & 61.0 \\ 1341-10-01 R & 5.0 & 71.0 \\ 1342-10-01 R & 3.9 & 55.0 \\ 1343-10-01 R & 5.2 & 74.0 \\ 1349-10-01 R & 4.8 & 68.0 \\ 1350-10-01 R & 5.5 & 78.0\end{array}$

HNAB

$\begin{array}{lll}1361-11-01 & 14.3 & 95.4 \\ 1362-11-01 & 14.5 & 96.6 \\ 1363-11-01 & 14.6 & 97.4\end{array}$

Six 20kg batches of picryl chloride were made with yields between 93 and $97 \%$. Four batches of HNHB $(20 \mathrm{~kg})$ were made with yields ranging between 90 and 958 . Eight $7 \mathrm{~kg}$ recrystallizations of $\mathrm{HNHB}$ were made with yields between 50 and $78 \%$. Three batches of HNHB were oxidized to HNAB with yields between 95 and $97 \%$ and a total production of over $44 \mathrm{kilograms.} \mathrm{(The} \mathrm{above} \mathrm{work} \mathrm{for} \mathrm{synthesis} \mathrm{of} \mathrm{HNAB}$ is primarily funded by Sandia P.0. 58-0060.)

Data for HNAB 1281-11-01R which was completed last quarter (but the data was not complete) is compared to 1194-11-OIR in Figs. 2, 3, 4 and 5, and Tables III, IV, $V$, and VI.

Purchase orders for DINOL (25 lbs) and DNPIA (50 lbs) were awarded to Aerojet. The expected delivery date is April 1, 1972. These materials will be used to make two $75 \mathrm{lb}$ lots of AFNOL.

FUTURE WORK; COMMENTS; CONCLUSIONS

The HNAB produced will be recrystallized and heat treated to complete the study on recrystallization.

The bis-HNHB will be oxidized to bis-HNAB and this material will be recrystal1ized. 
Existing quantities of triPEOA will be used to check out the molecular still. The purified triPEOA will be reconverted to triPEON.

Since the lab study on BTF synthesis is nearing completion, pilot scale work on this material can be started.

Lab scale work on nitration of TCB (trichlorobenzene) to TNTClB(trinitrotrichlorobenzene) will be started. 


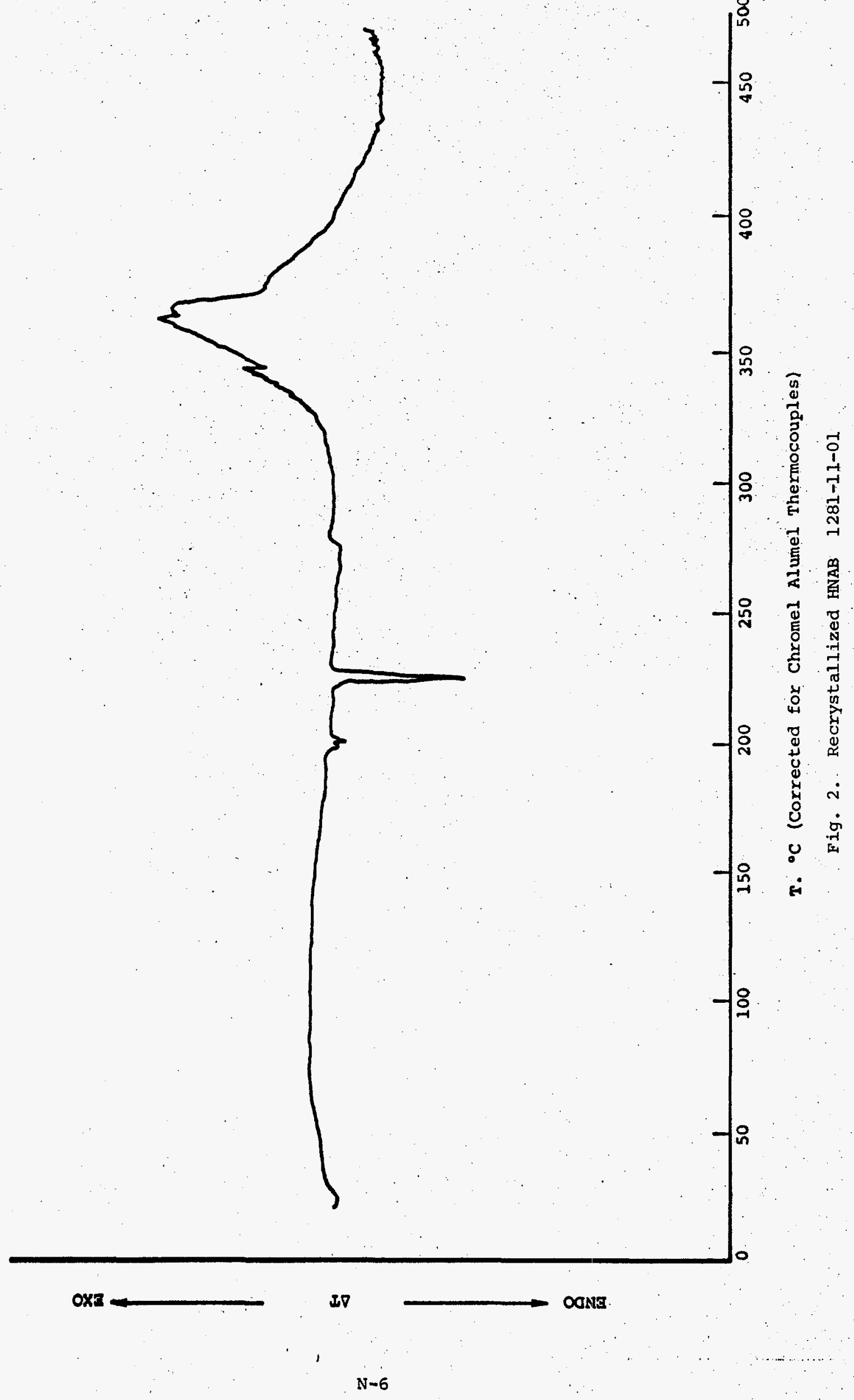




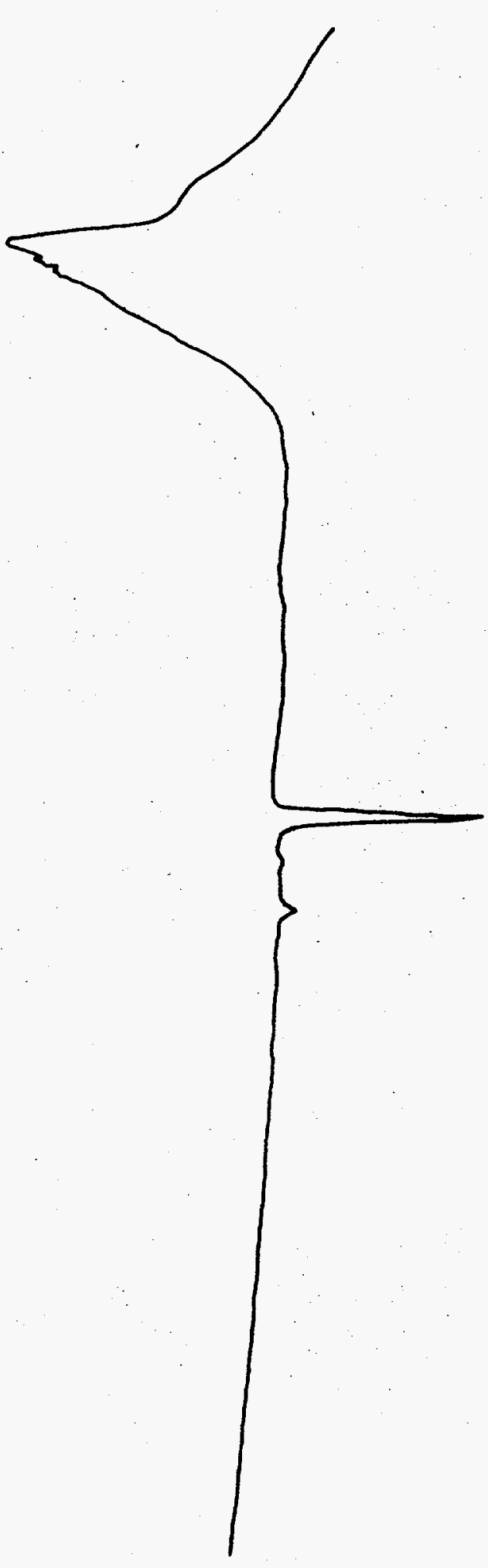

$-1 \begin{aligned} & 0 \\ & 0 \\ & \forall \\ & 0 \\ & m \\ & m\end{aligned}$

.

$-8$

응

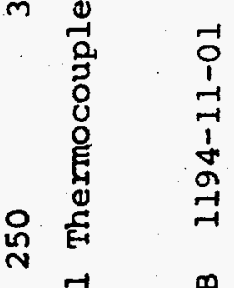

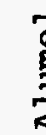

兽要

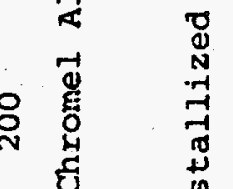

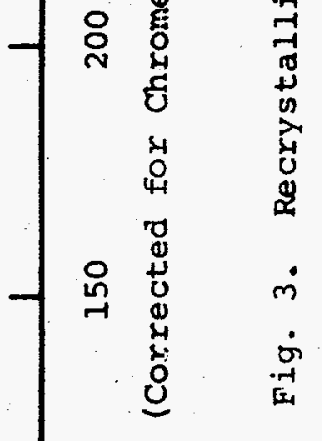

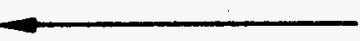

$$
\begin{gathered}
L \nabla \\
N-7
\end{gathered}
$$




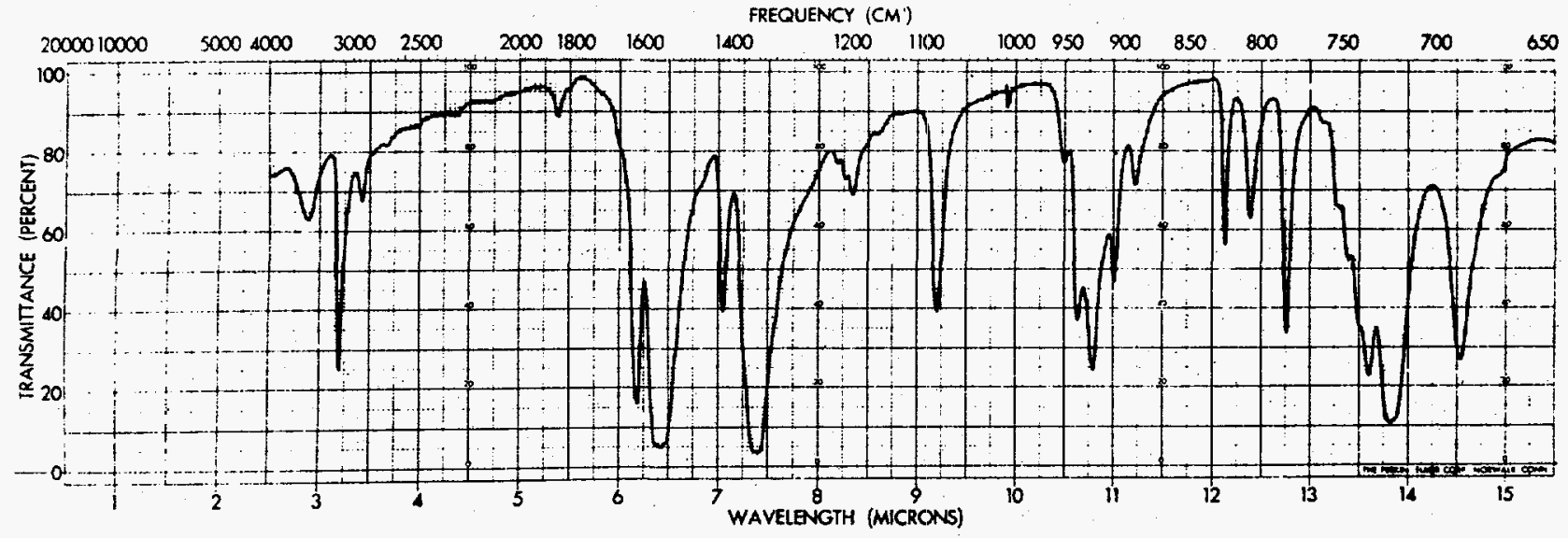

Fig. 4. Infrared spectrum 1194-11-01

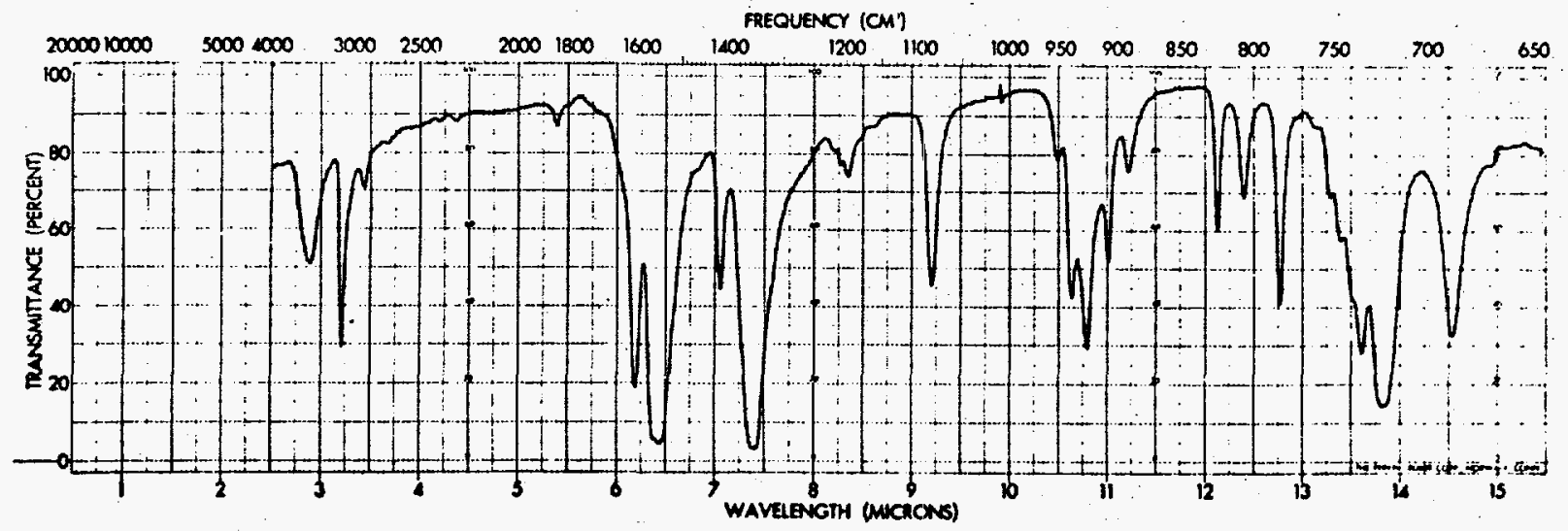

Fig. 5. Infrared spectrum 1281-11-01 
Table III. X-Ray Diffraction

HNAB 1194-11-01

Target $-\mathrm{Cu}, \theta_{1}=0, \lambda_{1}=1.5418$

\begin{tabular}{|c|c|c|c|c|}
\hline Iine & $S_{1}$ & dhkI & Qhkl & $\dot{I} / I_{0}$ \\
\hline 1 & 14.35 & 6.17 & 0.02625 & 10 \\
\hline 2 & 14.70 & 6.03 & 0.02754 & 30 \\
\hline 3 & 15.25 & 5.81 & 0.02963 & 15 \\
\hline 4 & 16.05 & 5.52 & 0.03279 & 5 \\
\hline 5 & 16.55 & 5.36 & 0.03486 & 2 \\
\hline 6 & 16.95 & 5.23 & 0.03655 & 2 \\
\hline 7 & 17.42 & 5.09 & 0.03859 & 20 \\
\hline 8 & 18.58 & 4.78 & 0.04385 & $100++$ \\
\hline 9 & 20.15 & 4.41 & 0.05150 & 65 \\
\hline 10 & 20.75 & 4.28 & 0.05457 & 55 \\
\hline 11 & 21.92 & 4.05 & 0.06082 & 100 \\
\hline 12 & 23.32 & 3.81 & 0.06873 & 100 \\
\hline 13 & 23.90 & 3.72 & 0.07214 & .20 \\
\hline 14 & 25.88 & 3.44 & 0.08438 & 30 \\
\hline 15 & 26.62 & 3.35 & 0.08918 & 20 \\
\hline 16 & 27.00 & 3.30 & 0.09170 & 50 \\
\hline 17 & 27.55 & 3.24 & 0.09540 & 3 \\
\hline 18 & 28.05 & 3.18 & 0.09883 & 40 \\
\hline 19 & 28.42 & 3.14 & 0.10140 & 3 \\
\hline 20 & 29.80 & 3.00 & 0.11125 & 4 \\
\hline 21 & 30.55 & 2.93 & 0.11679 & 30 \\
\hline 22 & 31.38 & 2.85 & 0.12321 & 20 \\
\hline 23 & 32.22 & 2.78 & 0.12956 & 30 \\
\hline 24 & 32.87 & 2.72 & 0.13470 & 3 \\
\hline 25 & 33.57 & 2.67 & 0.14033 & 60 \\
\hline 26 & 34.75 & 2.58 & 0.15006 & 40 \\
\hline 27 & 35.40 & 2.54 & 0.15554 & 3 \\
\hline 28 & 36.50 & 2.46 & 0.16503 & 10 \\
\hline 29 & 37.52 & 2.40 & 0.17404 & .5 \\
\hline 30 & 41.60 & 2.17 & 0.21219 & 20 \\
\hline
\end{tabular}


Table IV. X-Ray Diffraction

HNAB 1281-11-01

Target $-\mathrm{Cu}, \theta_{1}=0, \lambda_{1}=1.5418$

I.ne

1

2

3

4

5

6

7

8

9

10

11

12

13

14

15

16

17

18

19

20

21

22

23

24

25

26

27

28

29

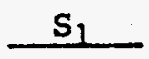

14.35

14.72

15.30

16.10

16.57

16.97

17.45

18.60

20.20

20.75

21.92

23.35

23.90

24.27

25.92

26.55

27.07

27.50

28.10

28.60

29.80

30.65

31.40

32.25

32.85

33.65

34.82

36.40

37.55 dhkl

6.172

6.018

5.791

5.505

5.350

5.225

5.082

4.770

4.396

4.281

4.055

3.810

3.723

3.667

3.437

3.357

3.294

3.243

3.175

3.121

2.998

2.917

2.849

2.776

2.726

2.663

2.576

2.468

2.395 ghk1

.02625

.02762

.02982

.03300

.03494

.03663

.03872

.04394

.05175

.05457

.06082

.06891

.07214

.07436

.08463

.08872

.09217

.09506

.09917

.10266

.11125

.11754

.12321

.12980

.13454

.14098

.15064

.16415

.17431
$I / I_{0}$

10

40

20

5

5

3

10

$100++$

95

55

20

90

35

2

25

2

40

3

45

4

5

40

30

30

2

50

10

15

10 
Table V. Random Sample for Impurity Particle Distribution HNAB 1194-11-01

Bottle No.

27

19

14

3

34

42

51

62

66

75
View A

$8>0.005$

$4>0.002$

$3>0.005$

$12>0.002$

$7>0.005$

$10>0.002$

$3>0.005$

$8>0.002$

$9>0.005$

$9>0.002$

$2>0.005$

$7>0.002$

$2>0.005$

$14>0.002$

$2>0.005$

$10>0.002$

$2>0.005$

$11>0.002$

$2>0.005$

$15>0.002$
View B

$$
\begin{aligned}
8 & >0.005 \\
10 & >0.002 \\
3 & >0.005 \\
14 & >0.002 \\
10 & >0.005 \\
11 & >0.002 \\
1 & >0.005 \\
10 & >0.002
\end{aligned}
$$

$3>0.005$

$4>0.002$

$2>0.005$

$13>0.002$

$2>0.005$

$10>0.002$

$2>0.005$

$15>0.002$

$4>0.005$

$20>0.002$

$2>0.005$

$11>0.002$ 
Table VI. Random Sample for Impurity Particle Distribution HNAB 1281-11-01

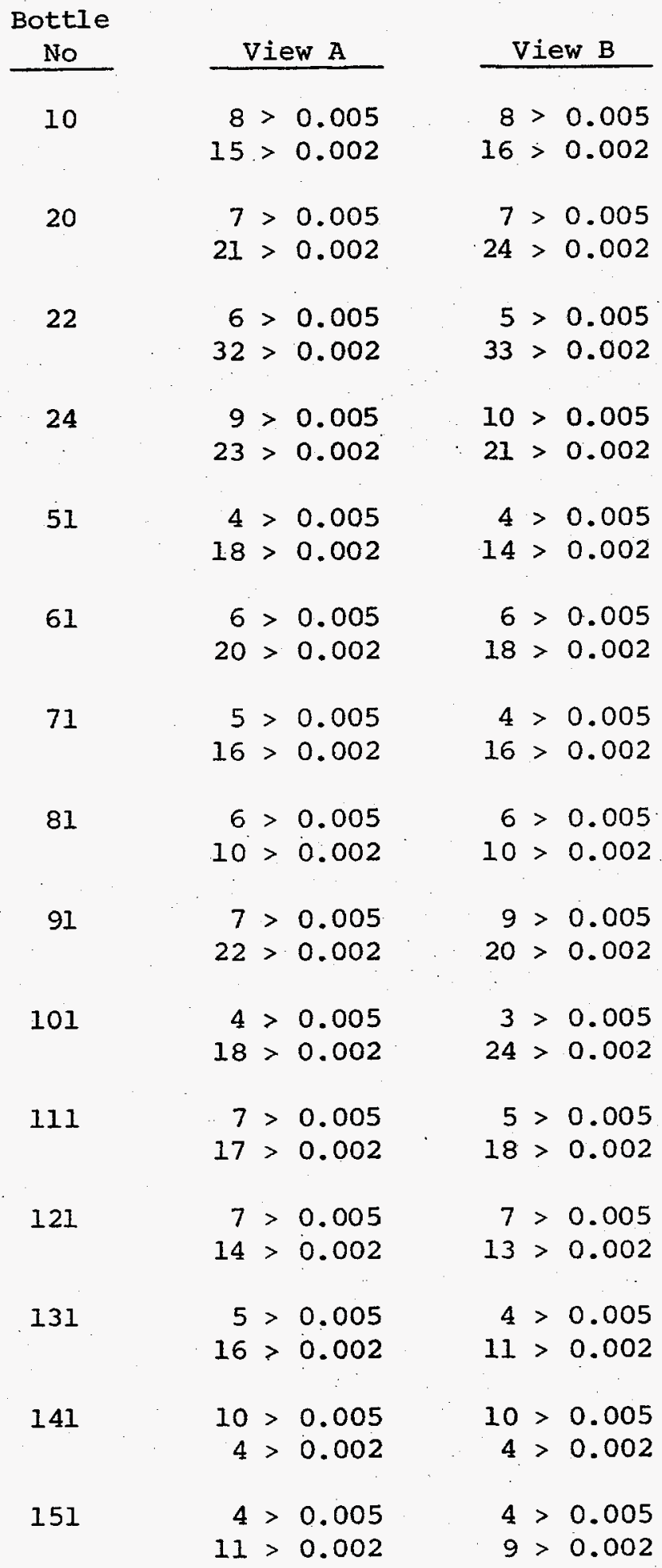

